Fábio Kummrow'

Dulce Magalhães"

Gisela de Aragão U mbuzeiro'v
Alexandre Franco"II

\section{Blue rayon e teste Salmonella/ microssoma na avaliação da qualidade de águas costeiras}

\author{
Blue rayon and Salmonella/ \\ microsome assay in the evaluation of \\ coastal water quality
}

\section{RESU MO}

OBJETIVO: Desenvolver estratégia para o monitoramento passivo das águas do estuário de Santos quanto à presença de atividade genotóxica e de hidrocarbonetos policíclicos aromáticos.

\begin{abstract}
MÉTODOS: Estudo realizado no estuário de Santos, Estado de São Paulo, em 2002. Foram selecionados e avaliados dois pontos de amostragem com diferentes graus de contaminação em duas campanhas de amostragem, utilizando a técnica de blue rayon in situ, análises químicas e o ensaio de Salmonella/microssoma com as linhagens bacterianas sensíveis a diferentes classes de compostos. Os extratos foram submetidos ao teste de Salmonella/microssoma em microssuspensão com as linhagens TA98, TA100, YG1041 e YG1042 na presença e ausência de ativação metabólica, e a análises químicas.
\end{abstract}

RESULTADOS: O ponto 1, que apresentou sedimento com altas concentrações de hidrocarbonetos policíclicos aromáticos, mostrou maior frequiência de resultados positivos para o ensaio Samonella/microssoma e maiores concentrações de hidrocarbonetos policíclicos aromáticos em ambas as campanhas em comparação com o ponto 2, menos contaminado. A linhagem que se mostrou mais sensível foi a YG1041, que permitiu comparações entre locais com diferentes graus de contaminação.

CONCLUSÕES: A combinação da técnica de blue rayon in situ com o ensaio Salmonella/microsoma com a linhagem YG1041 e as análises químicas se mostraram eficientes. Foi possível recuperar os compostos genotóxicos, e os hidrocarbonetos policíclicos aromáticos analisados, parecendo ser uma estratégia adequada para o monitoramento da qualidade das águas do estuário de Santos.

DESCRITO RES: Poluição dos estuários, prevenção e controle. Monitoramento da água. Hidrocarbonetos policíclicos aromáticos, genotoxicidade. Blue rayon. Salmonella/microssoma, monitoramento. Estuário de Santos.

\section{ABSTRACT}


Salmonella/microsome assay with bacterial strains sensitive to different compounds. The extracts were tested using the Salmonella/microsome assay in microsuspension with the strains TA98, TA100, YG1041, and YG1042 in the absence and presence of metabolic activation and through chemical analyses.

RESULTS: Site 1, which had high concentrations of polycyclic aromatic hydrocarbons in its sediment, showed more often positive results in the Salmonella/microsome assay as well as higher polycyclic aromatic hydrocarbons concentrations in both samplings compared to site 2, which was less contaminated. YG1041 strain showed to be the most sensitive allowing for comparisons between the sites with different levels of contamination.

CONCLUSIONS: The combination of the blue rayon hanging technique with the Salmonella/microsome assay using YG1041 strain and chemical analyses were effective in recovering genotoxins as well as polycyclic aromatic hydrocarbons tested in this study. Therefore this strategy seems to be adequate for water quality monitoring in Santos estuary.

KEYW O RD S: Estuary pollution, prevention \& control. Water monitoring. Polycyclic hydrocarbons, aromatic, genotoxicity. Blue rayon. Salmonella/ microsome, monitoring. Santos estuary.

\section{INTRODU ÇÃO}

Estuários são ecossistemas dinâmicos e produtivos de imenso valor ecológico e econômico, sendo de grande importância à compreensão do transporte e da distribuição dos contaminantes presentes nessas áreas. O Brasil possui 25 regiões metropolitanas das quais 14 estão localizadas em áreas estuarinas, onde estão instalados os principais pólos industriais e sistemas portuários. A região da Baixada Santista abriga, além do maior porto da América Latina (Porto de Santos), o maior pólo industrial do País e é considerada como o maior exemplo de degradação ambiental por poluição hídrica e atmosférica, de origem industrial, em ambientes costeiros do Brasil. ${ }^{12,19,21}$

Muitos trabalhos visando à avaliação da qualidade ambiental desse estuário já foram realizados. ${ }^{12,14,19,21}$ Pôde-se observar grande melhora na qualidade das águas em relação aos contaminantes avaliados, ${ }^{19}$ porém os sedimentos se apresentam ainda contaminados por hidrocarbonetos policíclicos aromáticos (HPA), ${ }^{12,14}$ entres outros compostos. Atividade genotóxica foi também observada nos locais mais impactados. ${ }^{19}$

Em relação às águas avaliadas não foram detectados HPA e a atividade genotóxica foi detectada em níveis muito baixos em alguns pontos específicos, não apresentando correlação direta com os dados obtidos para as amostras de sedimentos. ${ }^{19}$ Apesar disso, sabe-se que os sedimentos são importantes fontes de contaminação da coluna d'água, especialmente quando ressuspendidos (e.g.: atividades de navegação e dragagem). ${ }^{1,13}$

Os HPA são contaminantes ambientais ubiquitários encontrados no ar, no solo e na água. Esses contaminantes são compostos hidrofóbicos com dois ou mais anéis aromáticos fundidos, gerados durante a queima incompleta de matéria orgânica, naturalmente presentes no meio ambiente (e.g.: incêndios florestais naturais) ou relacionados a atividades humanas. Entre estas, destacam-se a produção de carvão Coque e gás, indústrias petroquímicas e produção de óleos combustíveis. ${ }^{17}$ Devido à persistência e ao potencial mutagênico/carcinogênico de vários HPA e seus derivados, freqüentemente têm sido realizados estudos sobre suas fontes/origem, ocorrência, transporte e comportamento nos diferentes compartimentos ambientais. ${ }^{22}$

Analisar quimicamente todos os contaminantes genotóxicos e seus produtos de transformação no meio ambiente é uma tarefa complexa. Por isso, bioensaios como o Salmonella/Microssoma (Teste de Ames) têm sido utilizados com sucesso para complementar as análises químicas na caracterização da qualidade das águas e dos sedimentos, ${ }^{1,16,20}$ especialmente de HPA, devido à sensibilidade desse teste a essa classe de compostos. Como as amostras ambientais são misturas complexas contendo compostos tóxicos e ou genotóxicos, o uso de técnicas seletivas de extração/concentração, como o blue rayon e/ou procedimentos de clean up, podem auxiliar a identificação de compostos presentes nos extratos obtidos. Se combinadas com linhagens seleti- 
vas de Salmonella typhimurium do Teste de Ames, podem sugerir as principais classes de contaminantes genotóxicos presentes no ambiente avaliado.

O blue rayon é o conjunto de fibras de raiom inertes ligadas covalentemente ao pigmento ftalocianina de cobre tiossulfato, um adsorvente seletivo para compostos orgânicos policíclicos, com três ou mais anéis fundidos em sua molécula. ${ }^{4}$ Quando utilizado in

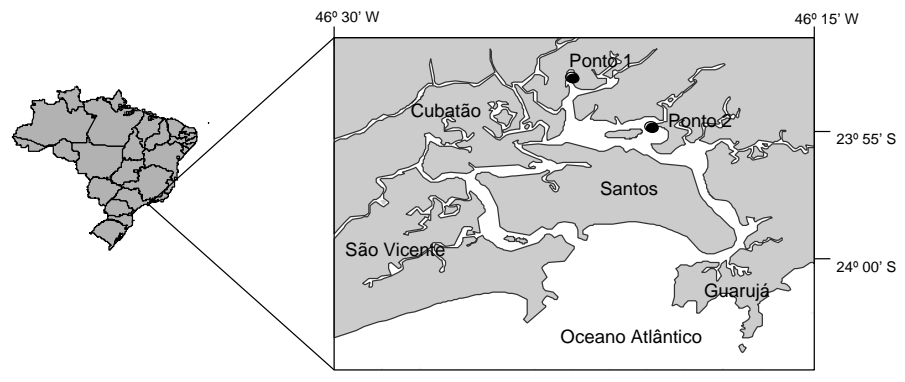
situ, as fibras de blue rayon permanecem imersas por $24 \mathrm{~h}$ nos locais de amostragem e após esse período, são recolhidas e levadas ao laboratório para a eluição e preparo dos extratos. ${ }^{18}$

A técnica de blue rayon in situ tem sido utilizada com sucesso para a recuperação de HPA e de compostos com atividade genotóxica ${ }^{6,7}$ em ambientes aquáticos. É utilizada especialmente em locais onde, por outros métodos de extração/concentração de amostras, os resultados observados para esses compostos estavam abaixo do limite de detecção. As principais vantagens dessa técnica são a dispensa de coleta de grandes volumes de amostras e maior representatividade da amostragem. ${ }^{8}$

É reconhecida a necessidade de se monitorar a qualidade das águas quanto à presença de compostos mutagênicos, especialmente onde há ressuspensão de sedimentos contaminados, como durante atividades portuárias. Assim, o objetivo do presente trabalho foi desenvolver uma estratégia para o monitoramento da qualidade das águas do estuário de Santos quanto à presença de HPA e de atividade mutagênica.

\section{MÉTO DOS}

Foram selecionados dois pontos de amostragem no estuário de Santos (Figura), sendo o ponto 1 (coordenadas geográficas S 2352'22,9”, W 46²2'44,2”) equivalente ao ponto 5 do estudo realizado pela Companhia de Tecnologia de Saneamento Ambiental (Cetesb) ${ }^{19}$ e o ponto 2 (coordenadas geográficas $\mathrm{S}$ 23⒌'17.1", W 46²0'09.1”) ao ponto 6 do mesmo estudo. Ambos estão sobre influência direta do regime de maré e recebem a drenagem dos municípios de Cubatão, Santos e Guarujá. A água é salobra nesses pontos. O ponto 1 recebe diretamente o despejo dos efluentes industriais de uma siderúrgica e de esgoto doméstico, e seu sedimento apresenta os maiores valores de HPA da região, chegando ao valor médio de $347 \mu \mathrm{g} / \mathrm{g} .{ }^{19} \mathrm{O}$ ponto 2 recebe principalmente esgoto doméstico e seu sedimento apresenta o valor médio de HPA de 0,6 $\mu \mathrm{g} / \mathrm{g}$. Ambos estão sob influência de atividades portuárias, como dragagem e navegação. ${ }^{19}$

As mechas de blue rayon, previamente lavadas e apresentando resultados negativos para o teste de Salmonella/microssoma em microssuspensão, ${ }^{10}$ foram acondicionadas em redes de nylon conectadas a uma poita $(5 \mathrm{~kg})$ por meio de um cabo de nylon a uma bóia. ${ }^{18}$ Os conjuntos foram colocados nos pontos de amostragem e as fibras permaneceram imersas por $24 \mathrm{~h}$. Em cada ponto foram colocados $20 \mathrm{~g}$ de blue rayon, divididos em quatro redes, cada uma com $5 \mathrm{~g}$ conectadas a $40 \mathrm{~cm}$ da poita, mantendo-se sempre a mesma distância entre o blue rayon e o sedimento. Após o período de $24 \mathrm{~h}$, o conjunto foi removido e as mechas de blue rayon foram levadas ao laboratório, em frasco coberto e ao abrigo da luz, para realização dos procedimentos de preparo dos extratos.

As mechas de blue rayon foram retiradas das redes e lavadas com água ultrapura (18,2 $\mathrm{M} \Omega$ ), para a retirada do material que ficou retido sobre as fibras, e não ligado às moléculas de ftalocianina de cobre tiossulfato, até que a água de lavagem se apresentasse límpida. $\mathrm{O}$ excesso de água foi retirado com papel filtro $\left(80 \mathrm{~g} / \mathrm{m}^{2}\right.$, $50 \times 50 \mathrm{~cm}$ ) limpo e as mechas transferidas para um erlenmeyer para serem eluídas com a solução de metanol/hidróxido de amônio 50:1 v/v na proporção de $200 \mathrm{ml}$ para cada $1 \mathrm{~g}$ de blue rayon. As fibras em contato com a solução de metanol/hidróxido de amônio $50: 1 \mathrm{v} / \mathrm{v}$ permaneceram sob agitação em agitador mecânico a $120 \mathrm{rpm}$ por cinco períodos de $1 \mathrm{~h}$, trocandose a solução de eluição a cada ciclo. Após esta etapa, a solução foi coletada em balões de evaporação e o solvente foi eliminado em evaporador rotatório com banho-maria a $40^{\circ} \mathrm{C}$. O extrato seco foi ressuspendido em volumes de 3 a $4 \mathrm{ml}$ de metanol e transferido para tubos de vidro limpos com tampa de teflon. Estes extratos foram armazenados à temperatura ambiente e ao abrigo da luz até o momento das análises.

Os extratos foram divididos em alíquotas, que foram submetidas a análises de genotoxicidade por meio do teste de Salmonella/microssoma em microssuspensão ${ }^{5}$ e ao fracionamento químico em colunas de sílica gel/alumina para clean up.

Com o objetivo de facilitar a identificação e quantifica- 
ção relativa dos HPA foi utilizada a técnica de fracionamento químico em colunas de sílica gel/alumina descrito por Grifoll et al. ${ }^{2}$ Alíquotas equivalentes 5 a $10 \mathrm{~g}$ de blue rayon dos extratos obtidos foram incorporadas a $1 \mathrm{~g}$ de alumina ativada e depositada sobre a coluna de fracionamento previamente preparada com $8 \mathrm{~g}$ de sílica na porção inferior e $7 \mathrm{~g}$ de alumina na porção superior. Em seguida foi lavada com $30 \mathrm{ml}$ de hexano, $30 \mathrm{ml}$ diclorometano (DCM), $30 \mathrm{ml}$ de metanol e $30 \mathrm{ml}$ de éter etílico, nesta sequiência. Foram utilizadas buretas de vidro de 10/350 mm com torneiras de teflon como suporte para a sílica gel/alumina.

Foram coletadas seis frações de polaridade crescente, sendo a primeira obtida pela adição de $20 \mathrm{ml}$ de hexano; a segunda, $20 \mathrm{ml}$ de solução $10 \%$ de DCM em hexano; a terceira, $40 \mathrm{ml}$ de solução $20 \%$ de DCM em hexano; a quarta, $20 \mathrm{ml}$ de solução $75 \%$ de DCM em hexano; a quinta, $40 \mathrm{ml}$ de solução $5 \%$ de metanol em DCM e a sexta, $40 \mathrm{ml}$ de éter etílico. Todas as frações foram coletadas individualmente e, após a secagem dos solventes sob fluxo de nitrogênio, foram submetidas ao teste de Salmonella/microssoma em microssuspensão ${ }^{5}$ para avaliação da atividade genotóxica. As frações número 3, nas quais são esperados os HPA, foram submetidas a análises cromatográficas para a identificação e quantificação relativa destes compostos. As frações número 5 foram avaliadas preliminarmente por cromatografia em fase gasosa acoplada a espectrômetro de massas.

Foram realizados controles negativos das colunas de sílica gel/alumina por meio do procedimento integral de fracionamento em colunas que não continham amostra.

Os HPA mutagênicos benzo(a)antraceno, criseno, benzo(b)fluoranteno, benzo(k)fluoranteno, benzo(e) pireno, benzo(a)pireno, indeno(1,2,3-cd)pireno, dibenzo(a,h)antraceno e benzo(g,h,i)perileno foram avaliados nas frações número 3 de todos os extratos por cromatografia em fase gasosa (CG), visando à sua identificação e quantificação relativa (massa dos HPA por grama de blue rayon). Na separação, foi utilizada uma coluna DB-5 (30 m x 0,25 mm x 0,25 $\mathrm{mm}$ ) em um cromatógrafo Shimadzu modelo GC-17 equipado com detector de ionização de chama (DIC). Todas as injeções foram realizadas em modo splitless e o volume injetado foi de $1 \mu \mathrm{l}$. As temperaturas do detector e do injetor foram $320^{\circ} \mathrm{C}$ e $300^{\circ} \mathrm{C}$ respectivamente. A temperatura do forno variou de $100^{\circ} \mathrm{C}(1$ $\mathrm{min})$ a $280^{\circ} \mathrm{C}(26,5 \mathrm{~min})$ com rampa de aquecimento de $8^{\circ} \mathrm{C}$ minn $^{-1}$. A identificação dos HPA nas amostras foi feita por comparação com os tempos de retenção de uma mistura de padrões do fabricante Supelco. O método do padrão externo foi usado na quantificação. Foram preparadas seis soluções de concentrações diferentes de uma mistura padrão de 16 HPA. Foram obtidas 16 curvas, uma para cada componente. Na quantificação do benzo(e)pireno foi usada a curva do benzo(a)pireno. Os coeficientes de correlação (R) obtidos para as curvas foram maiores que 0,9990 . Os limites de detecção variaram de 0,25 a 1,65 ng. Os resultados são expressos em ng de cada um dos HPA por grama de blue rayon pois pela técnica in situ não é possível precisar a quantidade de água que entrou em contato com as fibras.

Os extratos foram submetidos ao teste de Salmonella/ microssoma em microssuspensão, que é mais sensível que a técnica convencional ${ }^{5}$ e mais adequado quando se tem pequenas quantidades de amostra. Foram avaliadas quatro diferentes linhagens (Tabela 1), que detectam diferentes tipos de mutação na presença e ausência de ativação metabólica e, preferencialmente, distintas classes de compostos químicos. O sistema de ativação metabólica utilizado foi a fração S9 de fígado de rato Sprague Dawley induzido

Tabela 1 - Genótipo, tipo de mutação preferencialmente detectada e controles positivos das linhagens de Salmonella typhimurium utilizadas.

\begin{tabular}{|c|c|c|c|c|c|}
\hline $\begin{array}{l}\text { Linhagem } \\
\text { de Salmonella }\end{array}$ & Genótipo & $\begin{array}{l}\text { Tipo de mutação } \\
\text { detectada no DNA }\end{array}$ & Referência & - S9 Controles & $\begin{array}{l}\text { positivos } \\
+ \text { S9 }\end{array}$ \\
\hline TA98 & $\begin{array}{l}\text { HisD 3052, rfa, } \Delta \text { bio, } \Delta \text { uvrB, } \\
\text { pKM 101 }\end{array}$ & $\begin{array}{l}\text { Deslocamento no } \\
\text { quadro de leitura }\end{array}$ & $11 *$ & $\begin{array}{l}4-N Q O(0,125 \\
\mu \mathrm{g} / \mathrm{placa})\end{array}$ & $\begin{array}{l}\text { 2AA }(0,625 \\
\mu \mathrm{g} / \text { placa })\end{array}$ \\
\hline TA100 & HisG 46, rfa, $\Delta$ bio, $\Delta$ uvrB, pKM 101 & Troca de par de bases & $11 *$ & $\begin{array}{l}4-N Q O(0,125 \\
\mu \mathrm{g} / \mathrm{placa})\end{array}$ & $\begin{array}{l}\text { 2AA }(0,625 \\
\mu \mathrm{g} / \text { placa })\end{array}$ \\
\hline YG 1041 & $\begin{array}{l}\text { HisD } 3052 \text {, rfa, } \Delta \text { bio, } \Delta \text { uvrB, } \\
\text { pKM 101, pYG233 (produção } \\
\text { aumentada das enzimas } \\
\text { acetiltransferase e nitroredutase) }\end{array}$ & $\begin{array}{l}\text { Deslocamento no } \\
\text { quadro de leitura }\end{array}$ & $3^{*}$ & $\begin{array}{l}\text { 4-N O P } \\
(5 \mu \mathrm{g} / \text { placa })\end{array}$ & $\begin{array}{l}\text { 2AA }(0,03125 \\
\mu \mathrm{g} / \text { placa })\end{array}$ \\
\hline YG 1042 & $\begin{array}{l}\text { HisG } 46, \text { rfa, } \Delta \text { bio, } \Delta \text { uvrB, } \\
\text { pKM 101, pYG233 (produção } \\
\text { aumentada das enzimas } \\
\text { acetiltransferase e nitroredutase) }\end{array}$ & $\begin{array}{l}\text { Troca de par de } \\
\text { bases }\end{array}$ & 3* & $\begin{array}{l}2-N F(2,5 \\
\mu g / p l a c a)\end{array}$ & $\begin{array}{l}\text { 2AA }(0,625 \\
\mu \mathrm{g} / \text { placa })\end{array}$ \\
\hline
\end{tabular}

*Correspondente ao número na lista de referências.

4-N O O : 4-nitroquinolina-1-óxido

2-AA: 2-aminoantraceno

4-N OP: 4-nitro-o-diamino-fenilina

2-NF: 2nitrofluoreno 
Tabela 2 - Resultados obtidos no teste de Kado, em faixas de RM (razão de mutagenicidade) para os pontos 1 e 2, com as linhagens TA 98, YG 1041, TA 100 e YG 1042, na presença e na ausência de ativação metabólica (mistura S9). Santos, SP, 2002.

\begin{tabular}{|c|c|c|c|c|c|c|c|c|c|}
\hline \multirow[t]{2}{*}{ Frações } & \multirow[t]{2}{*}{ Campanhas } & \multicolumn{2}{|c|}{ TA 98} & \multicolumn{2}{|c|}{ YG 1041} & \multicolumn{2}{|c|}{ TA 100} & \multicolumn{2}{|c|}{ YG 1042} \\
\hline & & - S9 & +59 & - S9 & + S9 & -59 & +59 & - s9 & + S9 \\
\hline \multicolumn{10}{|c|}{ Ponto 1} \\
\hline \multirow[t]{2}{*}{ Total } & I & & & Tox & & NR & NR & & \\
\hline & II & & & & & & & & \\
\hline \multirow[t]{2}{*}{$F-1$} & 1 & & & & & & & & \\
\hline & II & & & Tox & Tox & & & & \\
\hline \multirow[t]{2}{*}{$F-2$} & $I$ & & & Tox & Tox & & & & \\
\hline & II & & & & & & & & \\
\hline \multirow[t]{2}{*}{$F-3$} & $\mathrm{I}$ & & & Tox & & & & & \\
\hline & II & & & & & & & & \\
\hline \multirow[t]{2}{*}{$F-4$} & 1 & & & & & & & & \\
\hline & II & & & & & & & & \\
\hline \multirow[t]{2}{*}{$F-5$} & 1 & & & & & & & & \\
\hline & II & & & & & & & & \\
\hline \multirow[t]{2}{*}{$F-6$} & $I$ & & & & & & & & \\
\hline & II & & & & & & & & \\
\hline \multicolumn{10}{|c|}{ Ponto 2} \\
\hline \multirow[t]{2}{*}{ Total } & $\mathrm{I}$ & & & & & & & & \\
\hline & II & & & & & & & & \\
\hline \multirow[t]{2}{*}{$F-1$} & $\mathrm{I}$ & & & & & & & & \\
\hline & II & & & & & & & & \\
\hline \multirow[t]{2}{*}{$F-2$} & 1 & & & & & & & & \\
\hline & II & & & & & & & & \\
\hline \multirow[t]{2}{*}{ F - 3 } & $\mathrm{I}$ & & & & & & & & \\
\hline & II & & & & & & & & \\
\hline \multirow[t]{2}{*}{$F-4$} & I & & & & & & & & \\
\hline & II & & & & & & & & \\
\hline \multirow[t]{2}{*}{$F-5$} & 1 & & & & & & & & \\
\hline & II & & & & & & & & \\
\hline \multirow[t]{2}{*}{$F-6$} & $I$ & & & & & & & & \\
\hline & II & & & & & & & & \\
\hline \multicolumn{10}{|c|}{$\begin{array}{l}\text { *NR: Teste não realizado } \\
\text { Legenda: Faixas de RM }\end{array}$} \\
\hline Tox & \begin{tabular}{ll|}
$\mathrm{RM}<0,7$ & 0
\end{tabular} \mid-2 & & $2 \mid-4$ & & $4 \mid-6$ & & & & \\
\hline
\end{tabular}

vos. Os resultados de RM menor que 0,7 foram considerados tóxicos. É possível que a toxicidade ocorra devido ao excesso de dano no DNA, o que causa a morte das bactérias-teste, bem como a presença de outros compostos não genotóxicos; porém, tóxicos às células bacterianas.

Para as linhagens utilizadas, respostas positivas na presença de ativação metabólica (mistura S9) e negativas na ausência de ativação metabólica, detectadas preferencialmente em frações apolares, podem ser atribuídas à presença de mutágenos indiretos, como os HPA não substituídos (ex: benzo(a)antraceno, benzo(b)fluoranteno, benzo(k)fluoranteno, benzo(a)pireno, criseno, dibenzo(a,h)antraceno e indeno (1,2,3-c,d)pireno).

\section{RESU LTADOS}

Os resultados do teste de Salmonellal microssoma em microssuspensão para os extratos totais e frações foram apresentados na Tabela 2 em faixas de razão de mutagenicidade (RM). As taxas de reversão médias obtidas para os controles negativos e positivos na ausência e na presença de $\mathrm{S} 9$ em número de revertentes por placa foram apresentados na Tabela 3 . com Aroclor 1254 (Moltox, Boone, NC), preparada no momento do ensaio na concentração de $4 \%$ v/v com adição dos cofatores adequados. ${ }^{11}$

Por se tratar de uma avaliação preliminar da atividade mutagênica, os experimentos foram realizados em dose única, referente à $0,5 \mathrm{~g}$ de blue rayon/placa, em triplicata, tanto para os extratos totais como para suas respectivas frações. A utilização de testes em dose única também se deve à limitada quantidade de extrato orgânico, que impossibilitou a realização de experimentos de dose resposta para a avaliação de potências genotóxicas nas frações e nos extratos totais com as diversas linhagens utilizadas.

O dimetilssulfóxido (DMSO) foi utilizado como solvente para os extratos totais e suas frações e como controle negativo dos experimentos. Os resultados do teste foram apresentados em faixas de razão de mutagenicidade (RM) já que é difícil realizar uma interpretação quantitativa de experimentos de dose única. A RM é calculada pela razão entre o número de revertentes obtidos nas placas teste e o número de revertentes dos controles negativos. Os resultados de RM maior que 2,0 foram considerados como positi-
A avaliação preliminar da atividade mutagênica testou os extratos e suas frações apenas em dose única. Apesar disso, foi possível verificar que o ponto 1 , que contém os sedimentos mais contaminados do estuário e está sujeito à influência direta de efluentes de coqueria, ${ }^{19}$ apresentou maior freqüência de resultados positivos e valores de RM maiores que o ponto 2 nas duas campanhas. Este ponto 2 apresentou resultados positivos apenas para a linhagem YG1041 na presença de $\mathrm{S} 9$ nos extratos totais das duas campanhas de amostragem e na fração 5 do extrato da segunda campanha (Tabela 2).

No que se refere à mutagenicidade das frações dos extratos obtidos no ponto 1 , observou-se que na primeira campanha as frações de número 2 a 6 apresentaram resultados positivos, sendo mais elevados nas frações 2, 3 e 5 para a TA98, especialmente na ausência de ativação metabólica. Para a YG1041, é provável que as doses testadas tenham sido muito altas, pois se observou toxicidade tanto para a fração total como para as frações menos polares (de números $1 \mathrm{a}$ 3). Isso indica excesso de dano ao DNA ou presença de compostos tóxicos mas não mutagênicos. $\mathrm{Na}$ se- 
Tabela 3 - Média de número de revertentes por placa das linhagens de Salmonella typhimurium na ausência e na presença de 59 para os controles negativos e positivos.

\begin{tabular}{|c|c|c|c|c|c|c|c|c|}
\hline \multirow[t]{2}{*}{ Controles } & \multicolumn{2}{|c|}{ TA98 } & \multicolumn{2}{|c|}{ YG1041 } & \multicolumn{2}{|c|}{ TA100 } & \multicolumn{2}{|c|}{ YG 1042} \\
\hline & -59 & +S9 & -59 & $+\mathrm{S} 9$ & -59 & +S9 & -59 & +59 \\
\hline $\begin{array}{l}\text { Negativos } \\
\text { Positivos* }\end{array}$ & $\begin{array}{c}27 \\
404\end{array}$ & $\begin{array}{c}26 \\
874\end{array}$ & $\begin{array}{c}120 \\
1.480\end{array}$ & $\begin{array}{c}99 \\
351\end{array}$ & $\begin{array}{c}114 \\
1.786\end{array}$ & $\begin{array}{c}120 \\
1.943\end{array}$ & $\begin{array}{c}88 \\
1.092\end{array}$ & $\begin{array}{c}84 \\
299\end{array}$ \\
\hline
\end{tabular}

*Consultar a Tabela 1 para informações sobre os compostos e doses utilizadas

gunda campanha, em relação à linhagem TA98, as frações de número 3, 5 e 6 foram positivas somente na ausência de $S 9$, resultado não observado para o extrato total. Tal fato se deve, provavelmente, à elevada dose de extrato total utilizada, que leva ao decréscimo das razões de mutagenicidade. No entanto, para a linhagem YG1041, o extrato total apresentou respostas ainda mais altas que as suas respectivas frações. Respostas similares foram observadas para a YG1042/TA100, porém em menor intensidade. Experimentos dose-resposta serão necessários para determinar a potência das frações totais, permitindo a avaliação quantitativa da resposta mutagência nos pontos estudados.

Os resultados das análises cromatográficas realizadas nas frações 3 dos extratos para identificação/quantificação relativa (em ng/g de blue rayon) dos HPA são apresentados na Tabela 4. A presença de HPA não substituídos foi verificada nos extratos da primeira campanha em ambos os pontos de amostragem e apenas no ponto 1 na segunda campanha. Foram observadas grandes variações nas concentrações desses compostos, tanto em relação aos pontos como entre as campanhas. Apesar da variabilidade dos dados, as águas do ponto 1 apresentaram concentrações relativamente maiores dos compostos analisados. Esses compostos poderiam explicar a mutagenicidade obtida, porém apenas aquela dependente de S9. Os resultados dos testes de mutagenicidade apontam também a presença de outros compostos com atividade genotóxica direta.

Além das frações 3, as frações 5 também indicaram importante atividade mutagênica em ambos os pontos de amostragem. Elas foram submetidas a análises químicas preliminares por cromatografia a gás acoplada a espectrometria de massas. Em ambos os pontos e nas duas campanhas foram detectados os seguintes compostos: 9H-fluoren-9-ona (CAS: 486-259), antraquinona (CAS: 85-68-1), 5H-fenantro[4,5bcd]piran-5-ona (CAS: 237-02-49-0), 7H-benzo[de] antracen-7-ona (CAS: 82-05-3), benzo(c)acridina (CAS: 225-51-4), 9-nitroso-9H-carbazol (CAS: 278823-0) entre outros. Apenas a antraquinona, 7H-benzo [de]antracen-7-ona e a benzo(c)acridina foram descritas como positivas para o teste de Ames. Para os demais compostos não foram encontrados dados na literatura consultada.

\section{DISCUSSÃO}

Em relação ao tipo de atividade mutagênica detectada no ponto 1 , foram observados resultados positivos tanto na presença quanto na ausência de mistura S9 nos extratos totais. Isso caracteriza a presença de compostos mutagênicos diretos, que não precisam ser bioativados por enzimas do citocromo P450 (mistura S9) e de compostos dependentes da ativação metabólica. Na segunda campanha a alta resposta do extrato total observada com a linhagem YG1041 em relação à TA98, sugere a presença de nitro-compostos na coluna d'água. Esse resultado é reforçado pela resposta da YG1042, que também é uma linhagem mais sensível a esta classe de compostos, e também apresentou respostas positivas frente aos extratos das duas campanhas. Os resultados positivos observados no ponto 2 para a linhagem YG1041 na presença de

Tabela 4 - Identificação e quantificação dos HPA nas frações 3 dos extratos de ambos os pontos, das duas campanhas com as concentrações em ng/g de blue rayon. Santos, SP, 2002.

\begin{tabular}{|c|c|c|c|c|c|c|}
\hline HPA & $T R$ & Branco & & & & 2 \\
\hline & Padrão & & Campanha & Campanha & Campanha & Campanha \\
\hline Benzo(a)antraceno & 22,492 & 0,6 & 2625,4 & 24,0 & 2,0 & - \\
\hline Criseno & 22,604 & - & 2761,6 & 42,1 & 4,0 & - \\
\hline Benzo (b)fluranteno & 25,805 & - & 957,7 & 12,5 & - & - \\
\hline Benzo(k)fluranteno & 25,888 & 1,0 & 906,2 & 2,7 & 4,1 & - \\
\hline Benzo(e)pireno & 26,795 & - & 878,5 & 21,4 & - & - \\
\hline Benzo(a)pireno & 26,871 & 1,1 & 1290,9 & 11,5 & - & - \\
\hline Indeno $(1,2,3-C D)$ pireno & 32,550 & - & 374,7 & - & - & - \\
\hline Dibenzo $(A, H)$ antraceno & 32,781 & 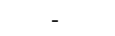 & 163,0 & - & - & - \\
\hline Benzo $(G, H, I)$ pirileno & 34,103 & - & 133,8 & 14,8 & - & - \\
\hline Somatório dos HPA & - & 2,7 & 10091,8 & 129,0 & 10,1 & - \\
\hline
\end{tabular}

TR padrão: Tempo de retenção padrão

HPA: Hidrocarbonetos polić́clicos aromáticos

- Abaixo do limite de detecção do método 
S9 e negativos para a TA98 podem sugerir a presença de compostos com atividade mutagênica indireta, tais como HPA não substituídos e algumas aminas aromáticas, para as quais esta linhagem é mais sensível.

Apesar das limitações dos resultados obtidos com experimentos de dose única, pode-se observar que as linhagens TA98 e YG1041 se mostraram mais sensíveis aos compostos genotóxicos presentes no ponto 1. Para o ponto 2, apenas a YG1041 apresentou respostas positivas. Portanto os dados sugerem que a YG1041 é mais adequada para o monitoramento da atividade mutagênica das águas desse estuário.

As altas concentrações de HPA observadas durante a primeira campanha no ponto 1 podem ser atribuídas tanto ao lançamento de efluentes contendo HPA durante o período de amostragem como ao fluxo de embarcações no cais da siderúrgica (que poderiam estar emitindo descargas contendo HPA provenientes da queima de combustíveis). Outra causa que não pode ser descartada é a ressuspensão do sedimento por meio da turbulência que a navegação é capaz de provocar, levando à presença de sedimentos contendo os HPA ou seus produtos de transformação na coluna d'água.

Na segunda campanha, foram observadas no ponto 1 concentrações mais baixas dos HPA apesar das elevadas concentrações desses compostos e da atividade genotóxica presente no sedimento desse local. ${ }^{19}$ Normalmente, os HPA estão presentes em baixas concentrações na coluna d'água devido a sua baixa polaridade. Por isso, tendem a ficar aderidos ao material particulado e ao sedimento. ${ }^{9,15,19} \mathrm{O}$ trabalho realizado por Nogami et a ${ }^{15}$ encontrou que $60-70 \%$ do total de benzo(a)pireno presente em amostras de água estão associados aos sólidos suspensos e apenas o restante na forma solúvel. Assim sugere-se que se não houver ressuspensão do sedimento a tendência é que os HPA estejam presentes na água em concentrações baixas.

As baixas concentrações de HPA e a baixa atividade genotóxica observada no ponto 2 são esperadas, uma vez que este local não está sob influência direta de fontes de HPA, como acontece no ponto 1. Essa baixa contaminação pode ser explicada pela deposição atmosférica e pela navegação existente na região.
Kira et al, ${ }^{8}$ utilizando a técnica de blue rayon in situ na região da Ilha Seto (Japão), verificaram a presença de benzo(a)pireno em água salgada em concentrações de 0,5 a 19,5 ng/g de blue rayon. Nesses extratos foi realizado o teste de Ames em dose única de $0,22 \mathrm{~g}$ equivalentes de blue rayon por placa com a linhagem YG1024 (similar a YG1041) na presença de S9 e os resultados, em RM, variaram entre de 3 e 14. Esses valores de RM foram similares à atividade mutagênica detectada no ponto 1 (Tabela 2). Porém Kira et $\mathrm{al}^{8}$ observaram que não há correlação direta entre o aumento nas concentrações de benzo(a)pireno e o aumento na atividade mutagênica. Em outro estudo, realizado por Kira et $\mathrm{al}^{7}$ na mesma região, foram detectadas concentrações de benzo(a)pireno entre 0,09 e $5,71 \mathrm{ng} / \mathrm{g}$ de blue rayon, valores inferiores àqueles observados em 1995.

Comparando-se os resultados da Ilha de Seto com os resultados do estuário de Santos, verificou-se que este último apresentou concentrações mais elevadas, chegando a até $1290,9 \mathrm{ng} / \mathrm{g}$ de blue rayon. Os resultados do teste de Salmonella/microssoma em microssuspensão, obtidos no presente trabalho, também não sugerem uma correlação entre as concentrações de HPA e a mutagenicidade detectada.

Em conclusão, a técnica de blue rayon in situ mostrou-se eficiente na recuperação de compostos policíclicos com atividade mutagênica. As análises químicas e o teste de mutagenicidade realizado indicaram que, além dos HPA, outros compostos mutagênicos estão presentes nas águas do estuário de Santos.

A combinação do ensaio Salmonella/microssoma em microssuspensão com técnica de blue rayon in situ parece ser uma estratégia adequada para o monitoramento eficiente da qualidade das águas dessa região em relação à presença de compostos genotóxicos, complementando as análises químicas. Entre as linhagens de Salmonella avaliadas no presente trabalho, a YG1041 se mostrou mais sensível e adequada para o monitoramento da qualidade das águas do estuário de Santos quanto à presença de compostos policíclicos genotóxicos, sendo capaz de discriminar locais com diferentes graus de contaminação. 


\section{REFERÊNCIAS}

1. Chen G, White PA. The mutagenic hazards of aquatic sediments: a review. Mutat Res. 2004;567(2-3):151-225.

2. Grifoll M, Solanas AM, Bayona JM. Characterization of genotoxic compounds in the sediment by mass spectrometric technics combined with Salmonella/ microssome test. Arch Environ Contam Toxicol. 1990;19:175-84.

3. Hagiwara $Y$, Watanabe $M, O$ da $Y$, Sofuni T, Nohmi T. Specificity and sensitivity of salmonella typhimurium YG 1041 and YG1042 strain possessing elevated levels of both nitroreductase and acetyltransferase activity. Mutat Res. 1993;291(3):171-80.

4. Hayatsu H. Cellulose bearing covalently linked copper phithalocyanine trisulphonate as na adsorbent selective for polycyclic compounds and its use in studies of environmental mutagens and carcinogens. J Chromatogr. 1992;597(1-2):37-56.

5. Kado NY, Langley D, Eisenstadt E. A simple modification of the salmonella liquid incubation assay. Mutat Res. 1983;121:25-32

6. Kira $S$, Ito $T$, Hayatsu $H$, Taketa $K$, Zheng $Y$, Li R, et al. Detection of waterborne mategens and characterization of chemicals in selected galveston sites after an oil spill. Bull Environ Contam Toxicol. 1994;53:285-91.

7. Kira S, Nogami $Y$, Ito $T, H$ ayatsu $H$. Mensurament of a time-weighted average concentration of polycycli aromatic hidrocarbons in seawater: an improved procedure of blue rayon hanging technique for monitoring benzo(a)pyrene. Mar Environ Res. 1998;46(1-5):267-71.

8. Kira S, Taketa K, Nogami Y, Hayatsu H. A simple technique for monitoring mutagenicity and benzo(a)pireno content in mussels and their ambient water. Environ Toxicol Water Qual. 1995;10:167-72.

9. Kot-Wasik A, Debska J, Namiesnik J. Monitoring of organic pollutants in coastal waters of Gulf of Gdansk, Southern Baltic. Mar Pollut Bull. 2004;49:264-76.

10. Kummrow $F$, Rech $C M$, Coimbrão $C A$, Roubicek DA, U mbuzeiro GA. Comparison of the mutagenic activity of XAD 4 and blue rayon extracts of surface water and related drinking water samples. Mutat Res. 2003;541(1-2):103-13.

11. Maron DM, Ames BN. Revised methods for the salmonella mutagenicity test. Mutat Res. 1983;113(34):173-215.
12. Medeiros PM, Bícego MC. Investigation of natural and anthropogenic hydrocarbons inputs in sediment using geochemical markers: Santos, SP-Brazil. Mar Pollut Bull. 2004;49(9-10):761-9.

13. Nipper M. Current approaches and future directions for contaminant-related impact assessment in coastal environments: Brazilian perspective. Aquat Ecosyst Health Manag. 2000;3:433-47.

14. Nishigima FN, Weber RR, Bícego MC. Aliphatic and aromatic hidrocarbons in sediments of Santos and Cananéia, SP, Brazil. Mar Pollut Bull. 2001;42:1064-72.

15. Nogami $Y$, Imaeda R, Ito T, Kira S. Benzo(a)pireno adsorbed to suspended solids in fresh water. Environ Toxicol. 2000;15:500-3.

16. O he T, Watanabe T, Wakabayashi K. Mutagens in surface waters: a review. Mutat Res. 2004;567(23):109-49.

17. Q uantin C, Joner EJ, Portal JM, Berthelin J. PAH dissipation in a contaminated river sediment under oxic and anoxic conditions. Environ Pollut 2005;134:315-22.

18. Sakamoto $H$, Hayatsu $H$. A simple method for monitoring mutagenicity of river water: mutagens in Yodo river system, Kyoto - O saka. Bull Environ Contam Toxicol. 1990;44:521-8.

19. Umbuzeiro GA, Kummrow F, Roubicek DA, Tominaga MY. Evaluation of the water genotoxicity from Santos Estuary (Brazil) in relation to the sediment contamination end effluent discharges. Environ Int. 2006;32:359-64.

20. Umbuzeiro GA, Roubicek DA, Sanchez PS, Sato MIZ. The salmonella mutagenicity assay in surface water quality monitoring program based on a 20 -year survey. Mutat Res. 2001;49(1-2):119-26.

21. U mbuzeiro GA, Roubicek DA, Stoppe NC, Rodrigues PF, Rech CM, Coimbrão CA, et al. Caracterização de amostras de sedimento hídrico do estuário de Santos utilizando análises de toxicidade aguda e genotoxicidade e quantificação de bactérias dos ciclos biogeoquímicos. Mundo Saúde. 2004;28:436-43.

22. Zhu L, Chen B, Wang J, Shen H. Pollution survey of polycyclic aromatic hydrocarbon in surface water of Hangzohou, China. Chemosphere. 2004;56:1085-95.

FK foi bolsista pela Coordenação para Aperfeiçoamento de Pessoal de Nível Superior (CAPES). 